\title{
EFICIÊNCIA NA EMERGÊNCIA E PRODUTIVIDADE DOS DIFERENTES TIPOS DE BATATA-SEMENTE
}

\section{EMERGENCY EFFICIENCY AND PRODUCTIVITY OF DIFFERENT POTATO SEED TYPES}

\author{
Alexsandro Lara TEIXEIRA ${ }^{1}$ \\ Camila Andrade SILVA ${ }^{2}$ \\ Leandro Santos PEIXOUTO ${ }^{3}$ \\ André Luiz LEPRE ${ }^{4}$
}

\section{RESUMO}

A batata-semente no Brasil é comercializada com base na sua massa e não no número de tubérculos, sendo este um fator que afeta sobremaneira o custo de produção, tornando imprescindível o conhecimento de como as características massa e eficiência na emergência da batata-semente influenciam no desempenho agronômico da cultura. O objetivo deste trabalho foi identificar o tamanho da batata-semente que possui maior eficiência na emergência e produtividade. Foram avaliados cinco tipos de classificação da batata-semente (I, II, III, IV e V), de acordo com a classificação do estado de Minas Gerais. O delineamento experimental utilizado no primeiro experimento foi o inteiramente casualizado (casa de vegetação), e nos dois experimentos conduzidos em campo utilizaram-se blocos casualizados, todos com cinco repetições. Os resultados obtidos demonstraram que existe diferença significativa para a maioria dos caracteres avaliados, exceto para massa média de tubérculos. Observou-se que quanto maior o tamanho do tubérculo da batata-semente, maior o número de olhos, brotos e consequentemente maior número de hastes. Foi possível verificar que quanto maior o tamanho da batata-semente maior será a produtividade $\left(\mathrm{t} \mathrm{ha}^{-1}\right)$, considerando o mesmo espaçamento entre plantas. O Tipo I de batata-semente é o que possui maior massa fresca. Existem diferenças quanto à produtividade, considerando o mesmo espaçamento, para os diferentes tipos de batata-semente, sendo o Tipo I o que apresenta maior produção de tubérculos comerciáveis.

Palavras-chave: Solanum tuberosum L.; tamanho do tubérculo; massa fresca.

\begin{abstract}
The potato seed in Brazil is marketed by mass and not on the number of tubers, which is a factor that affects on the cost of production, making essential the knowledge of how characters like weight and emergency efficiency of potato seed can influence the performance of culture. The purpose of this study was to identify the size of the potato seed that has greatest emergency and productivity. Five potato seed types (I, II, III, IV e V) were evaluated, according to the classification of the state of Minas Gerais. The experimental design used in the first trial was completely randomized (greenhouse), and in two field trials were used randomized complete block, all with five replications. The results showed that there is difference in most traits, except to average weight of tubers. It was observed that larger potato seed has more number of eyes, shoots and therefore more rods. It was noted that the larger potato seeds provide increases in productivity $\left(\mathrm{t} \mathrm{ha}{ }^{-1}\right)$, whereas the same spacing between plants. Type I potato seed has the higher fresh weight. There are differences in productivity, given the same spacing, for different types of potato seed, and the Type I has the highest tuber production.
\end{abstract}

Key-words: Solanum tuberosum L.; tuber size; fresh weight.

\footnotetext{
${ }^{1}$ D.Sc. Estudante, Genética e Melhoramento de Plantas, Universidade Federal de Lavras, Rua Renato A. de Pádua, 273/ap403, Vila Ester, 37200-000, Lavras, Minas Gerais, Brasil. E-mail: alexteixeira@hotmail.com. Autor para correspondência.

2 D.Sc. Estudante, Genética e Melhoramento de Plantas, Universidade Federal de Lavras, Lavras, Minas Gerais, Brasil. E-mail: camilaagro01@yahoo.com.br.

${ }^{3}$ M.Sc. Professor, Instituto Federal de Educação, Ciência e Tecnologia Baiano (IFBAIANO) - Campus Guanambi, Distrito de Ceraíma, Caixa Postal 09, Guanambi, Bahia, Brasil. E-mail: Ipeixouto@yahoo.com.br

4 M.Sc. Pesquisador, Geneze Sementes, Rodovia BR 040 - km 43.5, Caixa Postal 182, Paracatu, Minas Gerais, Brasil. E-mail: e.lepre@geneze.com.br.
} 
TEIXEIRA, A.L. et al. Eficiência na emergência e produtividade...

\section{INTRODUÇÃO}

No Brasil, a batata (Solanum tuberosum L.) é considerada uma das principais culturas, tanto em área cultivada quanto em preferência alimentar. Atualmente, a importação de semente básica de batata é inferior a $70 \%$, dependência que já foi superior em outras décadas (Dias, 2006). O país gasta por ano cerca de cinco milhões de dólares com a importação anual desse produto, o que corresponde entre 150 a 200 mil caixas (Dias, 2006). Nos últimos 20 anos houve um incremento na produção de sementes básicas no país com o objetivo de atender o mercado interno, ocasionado assim uma redução significativa na importação de sementes.

$\mathrm{Na}$ cultura da batata, a semente é uma unidade que merece atenção especial em toda a cadeia, pois, a partir da sua qualidade, do seu potencial e vigor é que se vislumbra e se persegue a oportunidade de atender ao consumidor com produtos de melhor qualidade e preço (Paes \& Silva, 2003). A batata-semente é o principal insumo e talvez aquele de maior custo relativo, mas também fundamental para o bom rendimento $\mathrm{e}$ retorno financeiro. A batata-semente no Brasil é comercializada com base na massa líquida da embalagem e não pela sua massa unitária ou conforme o número de tubérculos, sendo este um fator que afeta sobremaneira o custo de produção, tornando imprescindível o conhecimento de como as características massa, eficiência germinativa (número de brotos germinados viáveis) e eficiência na emergência (número de brotos germinados que romperam a camada superficial do solo) da batatasemente influenciam no desempenho agronômico da cultura. Em 2009, a caixa de batata-semente de $30 \mathrm{~kg}$ foi vendida ao preço médio de 25,00 dólares, sendo que esta é classificada de acordo com exigências internas dos países exportadores e não atendem as normas e regulamentos brasileiros (Deleo \& Gorino, 2009). Isso ocorre devido à falta de fiscalização (Bley, 2009) e pelo interesse dos fornecedores de batata-semente. Este fato prejudica o agricultor no momento da compra da semente, pois ele adquire tubérculos de vários tamanhos, sem opção de escolha. Na maioria dos casos o agricultor promove uma reclassificação dessa semente na própria propriedade, requerendo maior mão-de-obra e aumentando os custos de produção.

Como o número de hastes da planta afeta o tamanho e o número de tubérculos produzidos (Toosey, 1958; Corrêa et al., 2007), eles dependem consideravelmente do grau de dominância apical durante o armazenamento (Goodwin, 1963; Souza, 2003; Corrêa et al., 2007). Batatas-semente maiores normalmente desenvolvem maior número de brotos. Esta correlação também prevalece para o número de hastes, pois, de acordo com Allen (1978), o número de hastes aumenta com o tamanho da batata-semente. Caron \& Baldanzi (1965) comprovaram que, quanto maior o tamanho, mais precoce será o crescimento de brotos.
Tubérculos maiores possibilitam uma emergência mais rápida, com menor índice de falhas, e originam plantas com maior vigor e mais competitivas (Caron \& Baldanzi, 1965), o que sugere uma competição dos tubérculos formados por nutrien-tes (Gupta et al., 2003; Corrêa et al., 2007).

Tem sido demonstrado que o uso de batata-semente de maior massa proporciona maiores produtividades, tanto total (Guimarães \& Liberal, 1955; Paes \& Silva, 2003) quanto de tubérculos graúdos (Fontes \& Finger, 1999; Streck et al., 2007).

O objetivo deste trabalho foi identificar qual o tamanho de batata-semente possui maior resposta à emergência e produtividade.

\section{MATERIAL E MÉTODOS}

Os experimentos foram instalados no Departamento de Biologia, na Universidade Federal de Lavras (UFLA), Minas Gerais. Foram utilizados tubérculos de batata-semente, cultivar Atlantic, pertencentes ao programa de Melhoramento genético da Batata (PROBATATA) da UFLA. Inicialmente os tubérculos foram mantidos por um período de 50 dias em câmara fria, a fim de promover a quebra de dormência e indução da brotação. Foram conduzidos três experimentos, sendo um sob casa de vegetação e dois em campo. Em todos os experimentos foram avaliados os cinco tipos de batata-semente (I, II, III, IV e V), classificadas de acordo com o diâmetro transversal do tubérculo. A classificação seguiu as Normas Gerais para Certificação de Batata-Semente (BRASIL, 2003), sendo classificadas como: Tipo I entre 50 e $60 \mathrm{~mm}$; Tipo II - entre 40 e $50 \mathrm{~mm}$; Tipo III - entre 30 e $40 \mathrm{~mm}$; Tipo IV - entre 23 e $30 \mathrm{~mm}$ e Tipo V - menores que $23 \mathrm{~mm}$. O primeiro experimento foi conduzido em casa de vegetação, no período de 17 de outubro a 17 de novembro de 2007. O delineamento experimental utilizado foi o inteiramente casualizado, constituído de cinco tratamentos com cinco repetições, totalizando 25 parcelas. As parcelas foram constituídas de um tubérculo por vaso (vaso com capacidade para 5 litros) e o substrato comercial utilizado foi o Plantmax®. A contagem do número de olhos, brotos e massa das batatas-semente foram realizadas no mesmo dia do plantio. O número de hastes foi anotado durante o desenvolvimento inicial dos tubérculos ( $9,12,15$ e 18 dias). A colheita e análise da massa fresca (hastes coletadas a $2 \mathrm{~cm}$ do solo + folhas) dos tubérculos formados foram realizadas aos 30 dias após a emergência.

Os dois experimentos instalados no campo, foram conduzidos durante o período de agosto a novembro de 2008, em blocos casualizados, em que cada experimento foi constituído de cinco tratamentos com cinco repetições e parcelas de 3 linhas de $2 \mathrm{~m}$ e espaçamento entre linhas de 0,80 $\mathrm{m}$, totalizando 25 parcelas por experimento, sendo que apenas a linha central foi colhida para avaliação. No experimento $A$, os tratamentos foram plantados no mesmo espaçamento e no 
TEIXEIRA, A.L. et al. Eficiência na emergência e produtividade...

experimento $B$, os tratamentos foram plantados em diferentes espaçamentos (Tabela 1). Nesses experimentos foram avaliadas a produção de tubérculos comerciáveis: massa fresca de tubérculos com diâmetro transversal acima de 33 $\mathrm{mm}$, dividido pelo número de plantas da parcela ( $\mathrm{g}$ planta $\left.^{-1}\right)$; porcentagem de tubérculos graúdos: produção de tubérculos com diâmetro transversal acima de $45 \mathrm{~mm}$, dividido pela produção total de tubérculos comerciáveis da parcela, multiplicado por 100; e massa média de tubérculos: produção de tubérculos com diâmetro transversal acima de 33 $\mathrm{mm}$, dividido pelo número de tubérculos com diâmetro transversal acima de $33 \mathrm{~mm}$ (g/tubérculo). O solo foi preparado com aração, gradagem e sulcamento, ao qual aplicaram-se $3000 \mathrm{~kg} \mathrm{ha}^{-1}$ do formulado comercial 4-14-08 $\left(\mathrm{N}, \mathrm{P}_{2} \mathrm{O}_{5}, \mathrm{~K}_{2} \mathrm{O}\right)$. Trinta e cinco dias após o plantio foi realizada adubação de cobertura com sulfato de amônio, sendo utilizados $350 \mathrm{~kg} \mathrm{ha}^{-1}$, e efetuada a amontoa. O controle de plantas daninhas, insetos pragas, doenças e demais tratos culturais foi realizado conforme o manejo tradicional para a produção comercial de batata na região.

TABELA 1 - Detalhamento dos experimentos conduzidos em campo, com seu respectivo tipo de batatasemente, espaçamento entre plantas e número de plantas (linha de $2 \mathrm{~m}$ ) e seus respectivos resultados quanto à produção de tubérculos comerciáveis, porcentagem de tubérculos graúdos e massa média dos tubérculos. Lavras-MG, 2008.

\begin{tabular}{|c|c|c|c|c|c|c|c|}
\hline Experimento & Tratamento & Tipo & $\begin{array}{l}\text { Espaçamento } \\
\text { entre plantas } \\
\text { (m) }\end{array}$ & $\begin{array}{l}\mathrm{N}^{\circ} \text { de plantas } \\
\text { (linha de } 2 \mathrm{~m} \text { ) }\end{array}$ & $\begin{array}{c}\text { Produção } \\
\text { tubérculos } \\
\text { comerciáveis } \\
\left(\mathrm{t} \mathrm{ha}^{-1}\right)\end{array}$ & $\begin{array}{l}\text { Tubérculos } \\
\text { graúdos } \\
(\%)\end{array}$ & $\begin{array}{c}\text { Massa média } \\
\text { de tubérculos } \\
\text { (g) }\end{array}$ \\
\hline \multirow{5}{*}{$A$} & 1 & $\mathrm{I}$ & 0,25 & 8 & $20208,33 a^{1}$ & $34,06 a$ & $50,27 a$ \\
\hline & 2 & II & 0,25 & 8 & $18541,67 b$ & $34,75 a$ & $49,44 a$ \\
\hline & 3 & III & 0,25 & 8 & $12708,33 \mathrm{c}$ & $40,83 a$ & $56,11 a$ \\
\hline & 4 & IV & 0,25 & 8 & $5729,17 d$ & $8,83 b$ & $38,61 a$ \\
\hline & 5 & $\mathrm{~V}$ & 0,25 & 8 & $6875,00 d$ & $30,85 a$ & $45,00 a$ \\
\hline CV (\%) & & & & & 36,77 & 39,13 & 27,97 \\
\hline \multirow{5}{*}{ B } & 1 & 1 & 0,33 & 6 & $7708,33 \mathrm{~A}$ & $15,85 \mathrm{~A}$ & $41,62 \mathrm{~A}$ \\
\hline & 2 & II & 0,25 & 8 & $14270,83 \mathrm{~A}$ & $33,53 \mathrm{~A}$ & $47,12 \mathrm{~A}$ \\
\hline & 3 & III & 0,20 & 10 & $10520,83 \mathrm{~A}$ & $26,35 \mathrm{~A}$ & $50,74 \mathrm{~A}$ \\
\hline & 4 & IV & 0,14 & 14 & $6770,83 \mathrm{~A}$ & $11,11 \mathrm{~A}$ & $34,12 \mathrm{~A}$ \\
\hline & 5 & $\mathrm{~V}$ & 0,10 & 20 & $6979,17 \mathrm{~A}$ & $11,59 \mathrm{~A}$ & $44,41 \mathrm{~A}$ \\
\hline CV (\%) & & & & & 34,38 & 33,38 & 13,07 \\
\hline
\end{tabular}

${ }^{1}$ Médias seguidas da mesma letra minúscula ou maiúscula, na vertical, pertencem ao mesmo grupo, pelo teste de Scott \& Knott, $\mathrm{P} \leq 0,05$.

Para as análises de variância utilizou-se o procedimento GLM do pacote estatístico SAS (Statistical Analysis System).

\section{RESULTADOS E DISCUSSÃO}

Os resultados obtidos no primeiro experimento (Tabela 2) demonstraram que existe diferença significativa para todas as características avaliadas. Observou-se que quanto maior o tamanho do tubérculo de batata-semente, maior foi o número de olhos, de brotos e consequentemente maior número de hastes. Essas características apresentaram altos valores de correlações genéticas. É interessante ressaltar que para os caracteres olhos e brotos, a correlação foi de elevada magnitude $\left(r_{G}=0,96\right)$, e brotos com hastes $\left(r_{G}=0,97\right)$ (Tabela 3). Esses resultados confirmam as conclusões de Goodwin (1963) e Souza (2003), que verificaram que o número de hastes estaria relacionado com o número de brotos.

TABELA 2 - Médias das características avaliadas em casa de vegetação: massa do tubérculo, número de olhos, número de brotos, número de hastes aos 18 dias e massa fresca (hastes e folhas), determinadas por parcela. Lavras - MG, 2007.

\begin{tabular}{cccccc}
\hline \multirow{2}{*}{ TIPO } & \multicolumn{5}{c}{ Médias } \\
\cline { 2 - 6 } & $\begin{array}{c}\text { Massa do } \\
\text { tubérculo }(\mathrm{g})^{*}\end{array}$ & $\mathrm{~N}^{\circ}$ olhos $^{*}$ & $\mathrm{~N}^{\circ}$ brotos $^{*}$ & $\begin{array}{c}\mathrm{N}^{\circ} \text { de hastes } \\
(18 \text { dias })^{*}\end{array}$ & $\begin{array}{c}\text { Massa fresca } \\
(\mathrm{g})^{*}\end{array}$ \\
\hline I & $110,8 \mathrm{a}$ & $12,6 \mathrm{a}$ & $7,0 \mathrm{a}$ & $11,4 \mathrm{a}$ & $206,24 \mathrm{a}$ \\
II & $66,4 \mathrm{~b}$ & $10,8 \mathrm{a}$ & $3,2 \mathrm{~b}$ & $4,20 \mathrm{~b}$ & $160,68 \mathrm{~b}$ \\
III & $30,0 \mathrm{c}$ & $7,8 \mathrm{~b}$ & $1,4 \mathrm{c}$ & $2,80 \mathrm{~b}$ & $132,33 \mathrm{c}$ \\
IV & $11,6 \mathrm{~d}$ & $7,2 \mathrm{~b}$ & $1,0 \mathrm{c}$ & $2,00 \mathrm{~b}$ & $110,54 \mathrm{~d}$ \\
V & $7,2 \mathrm{e}$ & $7,0 \mathrm{~b}$ & $1,2 \mathrm{c}$ & $1,40 \mathrm{~b}$ & $76,46 \mathrm{e}$ \\
\hline $\mathrm{CV}(\%)$ & 25,48 & 33,21 & 26,01 & 55,23 & 8,20 \\
\hline
\end{tabular}

Médias seguidas por * diferem pelo teste $\mathrm{F}$ ao nível de $5 \%$ de probabilidade.

${ }^{1}$ Médias seguidas da mesma letra, na vertical, pertencem ao mesmo grupo, pelo teste de Scott \& Knott, P $\leq 0,05$. 
TEIXEIRA, A.L. et al. Eficiência na emergência e produtividade...

TABELA 3 -Correlações genéticas entre as características $n^{\circ}$ de olhos, $n^{\circ}$ de brotos, $n^{\circ}$ de hastes (18 dias), tamanho do tubérculo, produção de tubérculos comerciáveis, porcentagem de tubérculos graúdos e massa média de tubérculos, com espaçamento de 0,25 m entre plantas. Lavras-MG, 2007/2008.

\begin{tabular}{lc}
\hline \multicolumn{1}{c}{ Características } & Correlação Genética $\left(\mathrm{r}_{\mathrm{G}}\right)$ \\
\hline $\mathrm{N}^{\circ}$ de olhos $\times \mathrm{N}^{\circ}$ de brotos & 0,965 \\
$\mathrm{~N}^{\circ}$ de olhos $\times \mathrm{N}^{\circ}$ de hastes (18 dias) & 0,973 \\
$\mathrm{~N}^{0}$ de brotos $\times \mathrm{N}^{\circ}$ de hastes (18 dias) & 0,968 \\
Tamanho do tubérculo $\times$ Produção de tubérculos comerciáveis & 0,995 \\
Tamanho do tubérculo $\times$ \% de tubérculos graúdos & 0,644 \\
Tamanho do tubérculo x Massa média de tubérculos & 0,834 \\
Produção de tuber. comerciáveis $\times$ \% de tubérculos graúdos & 0,915 \\
Produção de tuber. comerciáveis $\times$ Massa média de tubérculos & 0,929 \\
\% de tubérculos Graúdos x Massa média de tubérculos & 0,996 \\
\hline
\end{tabular}

Por meio dos resultados apresentados na Figura 1, que mostra o número de hastes aos 9,12 , 15 e 18 dias após o plantio nos diferentes tratamentos, verifi-ca-se a influência do tamanho do tubérculo na formação de hastes ao longo do período de emergência. A batata-semente tipo I produziu maior número de hastes em relação aos outros tipos, evidenciando a sua superioridade em relação ao número total de hastes. Caron \& Baldanzi (1965), evidenciaram que em tubérculos maiores (tipo I e II), a emergência é mais precoce, comparado a tubérculos menores (tipo III e IV).

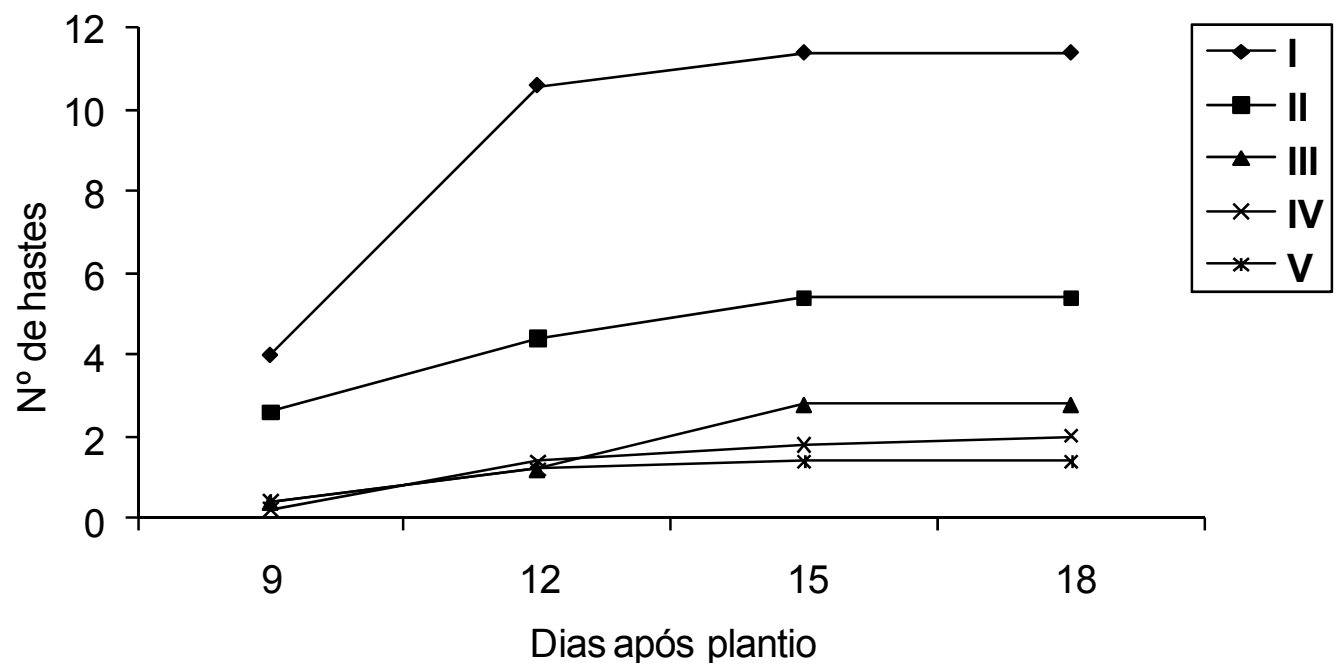

FIGURA 1 - Média do número de hastes por parcela aos 9, 12, 15 e 18 dias após o plantio nos diferentes tamanhos de batata-semente (I, II, III, IV e V). Lavras - MG, 2007.

A partir do gráfico apresentado na Figura 2, que ilustra o ajuste da produção de tubérculos comerciáveis $\left(\mathrm{t} \mathrm{ha}{ }^{-1}\right.$ ) em relação ao tamanho do tubérculo $(\mathrm{mm})$, é possível observar que quanto maior o tamanho da batata-semente maior será a produtividade (t ha $\left.{ }^{-1}\right)$, considerando o mesmo espaçamento entre plantas. 
TEIXEIRA, A.L. et al. Eficiência na emergência e produtividade...

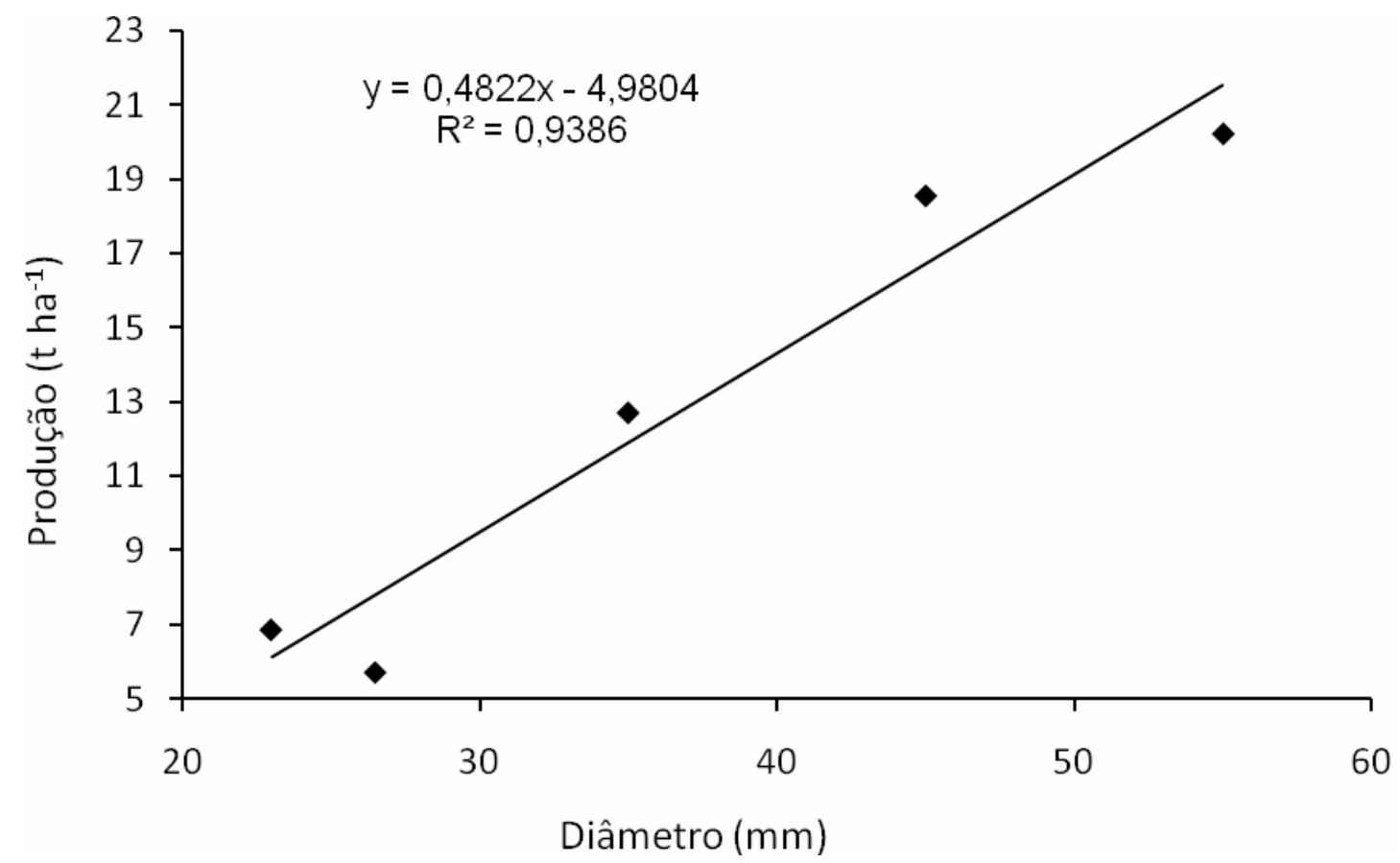

FIGURA 2 - Regressão linear simples (Significância $F(\%)$ : 0,75) da produção de tubérculos comerciáveis ( $t$ $\mathrm{ha}^{-1}$ ) em relação ao tamanho do tubérculo $(\mathrm{mm})$ no experimento conduzido em campo, com espaçamento de 0,25 m entre plantas. Lavras - MG, 2008.

Os resultados apresentados na Tabela 2 indicam que para os tratamentos submetidos a espaçamentos iguais (Experimento A), houve diferença significativa entre os tratamentos para produtividade e porcentagem de tubérculos graúdos (dados não apresentados). Foi encontrada alta correlação $(0,94)$ entre o tamanho da batatasemente e a produção de tubérculos comerciáveis (Tabela 3), sendo possível inferir que, para o espaçamento entre plantas de $25 \mathrm{~cm}$, quanto maior o tamanho da batata-semente maior será a produtividade de tubérculos. Apesar de ter sido constatada maior porcentagem de tubérculos graúdos no tamanho tipo III, essa diferença em relação aos tipos I e II foi não significativa (Scott Knott à $5 \%$ ).

Já para o experimento $B$, em que se procurou adequar a diferença entre os diferentes tamanhos de batata-semente, por meio da alteração do espaçamento entre plantas, nenhuma característica apresentou diferença significativa (Tabela 2). Esse fato indica que por meio de ajustes no espaçamento entre tubérculos, de acordo com o tipo de batata-semente, é possível uniformizar as diferenças de produtividade. Resultados semelhantes foram obtidos por Gupta et al. (2003), que utilizando plantas micropropagadas observaram que uma alta densidade de plantas (86 plantas $\mathrm{m}^{-2}$ ) proporcionou a produção, em média, de 5,9 tubérculos planta, ao passo que, em uma densidade menor (36 plantas $\mathrm{m}^{-2}$ ), a produção foi de 5,3 tubérculos por planta (diferença de 11\%). Corrêa et al. (2007) detectaram variações em diferentes densidades de plantio para a cultivar Monalisa. Os autores observaram que o número de tubérculos aumenta de forma linear à medida que aumenta a densidade de plantas, em contrapartida, o tamanho desses tubérculos é reduzido. Levando em conta o custo da batata-semente, a maior produtividade devida à alta densidade não compensaria, já que seria necessário dobrar o número de batatas-semente por $\mathrm{m}^{2}$.

\section{CONCLUSÕES}

1. O Tipo I de batata-semente possui maior massa fresca comparada aos demais tipos (II, III, IV e V).

2. Existem diferenças quanto à produtividade, considerando o mesmo espaçamento, para os diferentes tipos de batatasemente, sendo o Tipo I o que apresenta maior produção de tubérculos comerciáveis. 
TEIXEIRA, A.L. et al. Eficiência na emergência e produtividade...

\section{REFERÊNCIAS}

1. ALLEN, E. J. Plant density. In: HARRIS, P. M. (Ed.). The potato crop: the scientific basis for improvement. London: Chapman \& Hall, 1978. p. 279-326.

2. BLEY, S. Batata Semente-nosso principal insumo, nosso maior problema. Revista Batata Show. ano 9 , n. 23 , p. $8,2009$.

3. BRASIL. Portaria $n^{\circ} 567$, de 30 de janeiro de 2003. Dispõe sobre normas, padrões e procedimentos para certificação de material propagativo de batata no estado de Minas Gerais. Ministério da Agricultura, Pecuária e Abastecimento. Belo Horizonte: IMA, 30 jan. 2003.

4. CARON, A. G.; BALDANZI, G. Influência do peso do tubérculo-semente sobre a produção da cultura. Revista da Agricultura, v. 60, n. 1, p. 43-70, 1965.

5. CORRÊA, R. M. et al. Densidade de plantas e métodos de colheita na multiplicação de batata-semente em vasos. Horticultura Brasileira, v. 25, n. 2, p. 270-274, 2007.

6. DELEO, J. P. B.; GORINO, C. Gestão sustentável da bataticultura. Revista Hortifruti Brasil, ano 8, n. 84, p. 6-16, 2009.

7. DIAS, J. A. C. S. Produção de mini-tubérculos de batata-semente. 2006. Disponível em: <http://www.infobibos.com/ artigos/2006_3/minituberculos>. Acesso em: 6 set. 2009.

8. FONTES, P. C. R.; FINGER, F. L. Dormência dos tubérculos, crescimento da parte aérea e tuberização da batateira. Informe Agropecuário, v. 20, n. 197, p. 24-29, 1999.

9. GOODWIN, P. B. Mechanism and significance of apical dominance in the potato tuber. In: IVINS, J. D.; MILTHORPE, F. L. (Ed.). The growth of the potato. London: Butterworths, 1963. p. 63-71.

10. GUIMARÃES, F. F.; LIBERAL, M. T. Influência do peso dos tubérculos-semente no rendimento da batata americana (Solanum tuberosum L.). Agronomia Sulriograndense, v. 2, n. 1, p. 3-15, 1955.

11. GUPTA, V. K. et al. Effect of planting density on mini-tuber production from micropropagation plants. Journal of the Indian Potato Association, v. 30, n. 3-4, p. 43-44, 2003.

12. PAES, A. P. M.; SILVA, J. X. A importância da qualidade da batata-semente na redução do custo de produção. In: SEMINÁRIO MINEIRO DE BATATICULTURA, 4., 2003, Poços de Caldas. Anais... Poços de Caldas: Gráfica Irmão Gino, 2003. p. $55-58$.

13. SOUZA, Z. S. Ecofisiologia. In: PEREIRA, A. S.; DANIELS, J. (Ed.). O cultivo da batata na região sul do Brasil. Brasília: EMBRAPA, 2003. p. 80-104

14. STRECK, N. A. et al. Simulating the development of field grown potato (Solanum tuberosum L.). Agricultural and Forest Meteorology, v. 142, n. 1, p. 1-11, 2007

15. TOOSEY, R. D. Effect of number of sprout per set on yield and grading of main-crop potatoes. Nature, v. 182, n. 4630 , p. 269-270, 1958. 